\begin{tabular}{|c|c|}
\hline \multirow{3}{*}{ 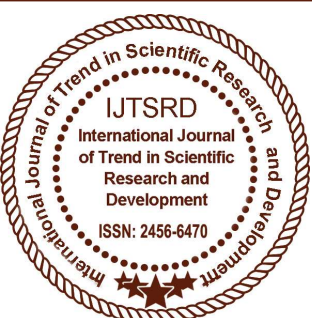 } & $\begin{array}{l}\text { International Journal of Trend in Scientific } \\
\text { Research and Development (IJTSRD) }\end{array}$ \\
\hline & Access Journal \\
\hline & ISSN No: $2456-6470$ | www.ijtsrd.com | Volume - 2 | Issue -4 \\
\hline
\end{tabular}

\title{
Comparison between FPGA Implementation of Discrete Wavelet Transform, Dual Tree Complex Wavelet Transform and Double Density Dual Tree Complex Wavelet Transform in Verilog HDL
}

\author{
Richa Srivastava ${ }^{1}$, Dr. Ravi Mishra ${ }^{2}$ \\ ${ }^{1}$ M.Tech Scholar, ${ }^{2}$ Sr. Assistant Professor
}

Shri Shankaracharya College of Engineering and Technology, Bhilai, Chhattisgarh, India

\section{ABSTRACT}

In recent world video and image compression, enhancement, restoration have become very essential. There are many applications where we need to use different transform techniques to convert the signal or data in frequency or time domain. However, with the wide spread of image usage in many fields of our lives, it becomes very important to develop new techniques. The previous research was based on Discrete wavelet transform. In this paper, 1 we introduce Dual tree Complex Wavelet Transform and Double Density Complex Wavelet Transform for applications such as image restoration and enhancement. This introduces limited redundancy (4:1 for 2-dimensional signals) and allows the transform to provide approximate shift invariance and directionally selective filters (properties lacking in the traditional wavelet transform) while preserving the usual properties of perfect reconstruction and computational efficiency. We show how the dual-tree complex wavelet transform and Double Density complex wavelet transform can provide a good basis for multiresolution image denoising and de-blurring.

Keywords: compression, double density complex wavelet transform, invariance, multiresolution, redundancy

\section{INTRODUCTION}

The Discrete Wavelet Transform (DWT) has become a very versatile signal processing tool over the last decade. In fact, it has been effectively used in signal and image processing applications. Wavelet transforms provide a framework in which an image is decomposed, with each level corresponding to a coarser resolution band. Once the wavelet transform is implemented, every second wavelet coefficient at each decomposition level is discarded, resulting in components that are highly dependent on their location in the sub sampling vector and with great uncertainty as to when they occurred in time. This unfavorable property is referred to as shift variance (throwing away 1 of every 2 samples). Coupled with the limitations in the direction, wavelet analysis thus cannot accurately represent the directions of the edges of images. To overcome these shortcomings of DWT, in 1998 Kingsbury proposed the dual-tree complex wavelet transform (DTCWT), an over-complete wavelet transform which provides both good shift invariance and directional selectivity. The DTCWT idea is based on the use of two parallel trees, one for the odd samples and the other one for the even samples generated at the first level. These trees provide the signal delays necessary for every level and hence eliminate aliasing effects and achieve shift invariance..Traditionally, this is achieved by linear processing such as Wiener filtering. A variety of methods have emerged recently on signal denoising using nonlinear techniques in the case of additive Gaussian noise. To denoise the image we study the Dual Tree Complex Wavelet Transform method first then we study the Double Density Complex Wavelet Transform and compare advantages $\&$ disadvantages of boththe methods. Comparison gives a new hybrid model which has the characteristics of both the methods Dual Tree Complex wavelet Transform \& Double Density Complex Wavelet Transform. 


\section{DUAL TREE COMPLEX WAVELET TRANSFORM}

The use of complex wavelets in image processing was originally set up in 1995 by J.M. Lina and L. Gagnon in the framework of the Daubechies orthogonal filters banks. The complex wavelet transform (CWT) is a complexvalued extension to the standard discrete wavelet transform (DWT)Dual tree complex wavelet transform is relatively recent enhancement to DWT with critical extra properties: It is nearly shift invariant and directionally selective in two and higher dimensions. It achieves this with a redundancy factor of only $2 \mathrm{~d}$ substantially lower than the undecimated DWT[1]. The multidimensional dual tree CWT is nonseparable but is based on computationally efficient, separable filter bank.

Making the wavelet responses analytic is a good way to halve their bandwidth and hence minimise aliasing. But we cannot use complex filters in to obtain analyticity and perfect reconstruction together, because of conflicting requirements[9]. Analytic filters must suppress negative frequencies, while perfect reconstruction requires a flat overall frequency response. So we use the Dual Tree:-

- to create the real and imaginary parts of the analytic wavelets separately, using 2 trees of purely real filters;

- to efficiently synthesise a multiscale shift-invariant filter bank, with perfect reconstruction and only 2:1 redundancy (and computation);

- to produce complex coefficients whose amplitude varies slowly and whose phase shift depends approximately

linearly on displacement[10]

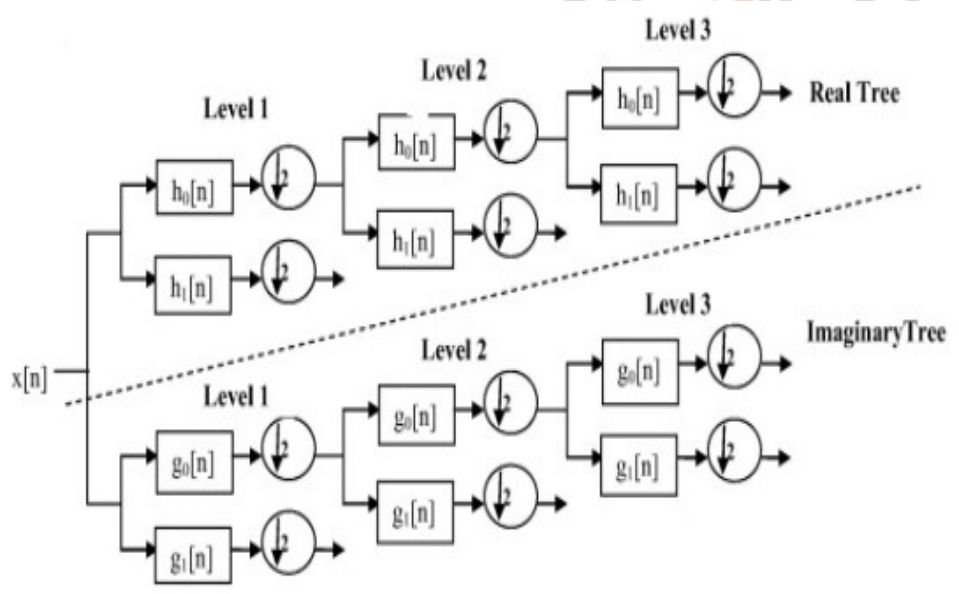

Fig: Block diagram of 2D -DTCWT

In dual tree complex wavelet transform input image is splitted into 16 levels with the help of two separable
2D-DWT out of which 12 are of high sub-bands and 4 are of low sub-bands [14]. As a result, sub bands of 2D DT-CWT at

each level are obtained as:

$(\mathrm{LHa}+\mathrm{LHb}) / \sqrt{ } 2,(\mathrm{LHa}-\mathrm{LHb}) / \sqrt{ } 2$,

$(\mathrm{HLa}+\mathrm{HLb}) / \sqrt{ } 2,(\mathrm{HLa}-\mathrm{HLb}) / \sqrt{ } 2$,

$(\mathrm{HHa}+\mathrm{HHb}) / \sqrt{ } 2,(\mathrm{HHa}-\mathrm{HHb}) / \sqrt{ } 2$

\section{III.DOUBLE DENSITY DUAL-TREE COMPLEX WAVELET TRANSFORM}

The utility of wavelets to signal and photo compression and to denoising is nicely searched. Orthogonal wavelet decompositions, based on separable, multirate filtering structures have been largely used in picture and signal processing in for information compression. Complex wavelets have not been used extensively in image processing due to the difficulty in designing complicated filters which fulfill a perfect reconstruction belonging . To overcome this problem a dual tree implementation of the Complex Wavelet Transform was proposed which uses two trees of real filters to generate the real and imaginary parts of the wavelet coefficients

The implementation of 2D DT CWT has following steps:

1. An input image is decomposed up to a desired level by two separable 2D DWT branches, branch $a$ and branch $b$, whose filters are specifically designed to meet the Hilbert pair requirement.

2. Then six high-pass sub bands are generated at each level. HLa, LHa, HHa, HLb, LHb and HHb.

3. Every two corresponding sub bands which have the same pass-bands are linearly combined by either averaging or differencing. As a result, sub bands of 2D DT-CWT at each level.

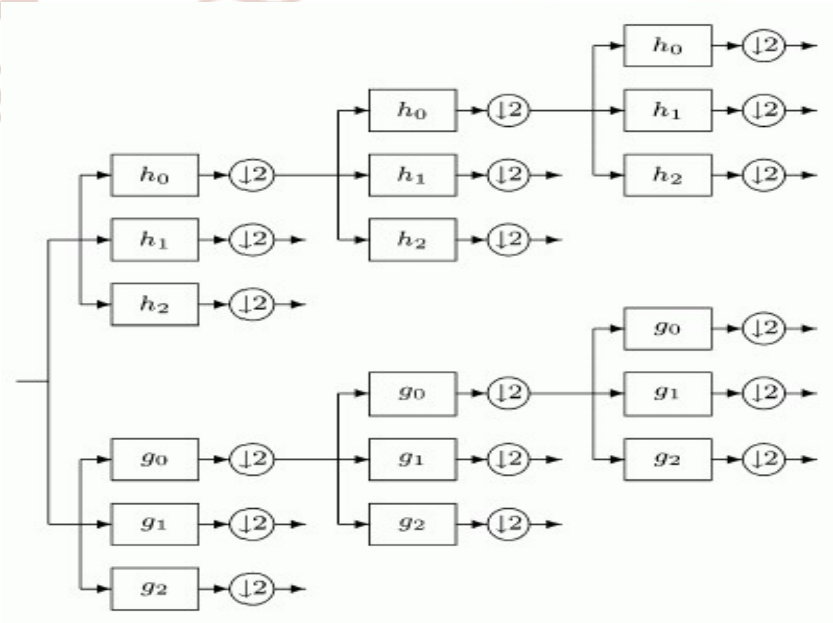

FIG: Iterated Filter bank for the Double-Density dual Tree Complex discrete WT 
International Journal of Trend in Scientific Research and Development (IJTSRD) ISSN: 2456-6470

Flow diagram below shows the proposed methodology. We started our work with input image. The input image is processed into MATLAB with use of suitable commands to convert into its pixel values. The data is stored in internal memory using a text file which contain input image pixel values in Verilog. The design of DWT hardware uses the concept of Harr transform because of simplicity and less hardware requirement for its implementation. In this algorithm average the two pixel values and this average will give average and difference component

\section{Proposed Methodology during the Tenure of Research Work}

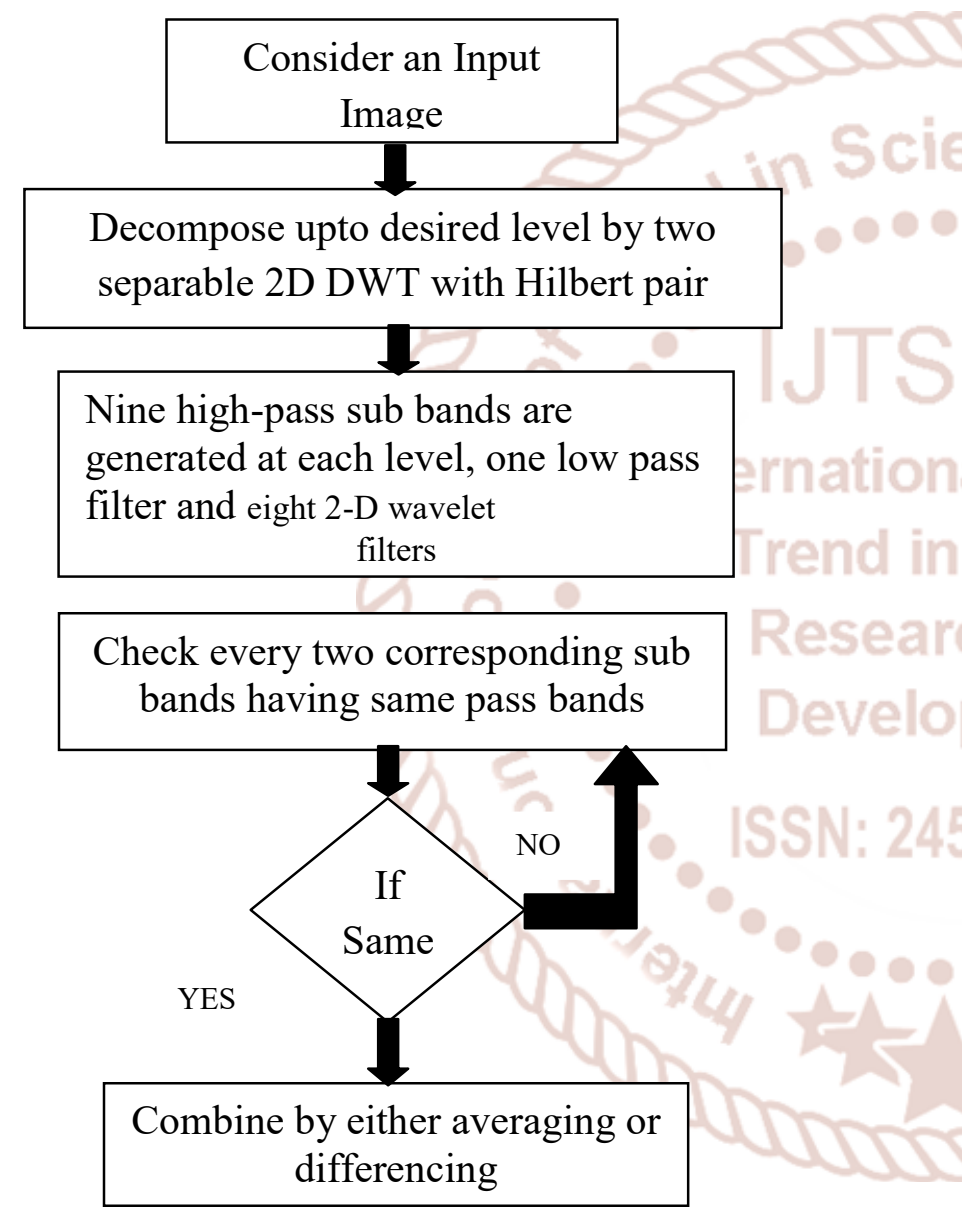

\section{CONCLUSION}

This paper highlighted design of dual tree complex wavelet transform (DTCWT) architecture AND Double density dual tree complex wavelet transform(DDDT CWT). The computed system can be implemented in MATLAB and Verilog HDL, later on this result is validated on FPGA Spartan 6. The pixel values of input image were operated using harr wavelet transform. The result portrayed us that the proposed architecture provides to retain important edge information without significant humming artifacts as compared to dual tree complex wavelet transform. It also provides perfect linear reconstruction using short linear phase filters and increased shift invariance and orientation selectivity

\begin{tabular}{|c|c|c|c|}
\hline Features & $\begin{array}{l}\text { Discrete } \\
\text { Wavelet } \\
\text { Transform } \\
(D W T)\end{array}$ & $\begin{array}{l}\begin{array}{l}\text { Dual Tree } \\
\text { Complex } \\
\text { Wavelet } \\
\text { Transform }\end{array} \\
\text { (DTCWT) }\end{array}$ & 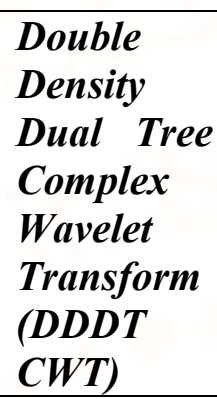 \\
\hline $\begin{array}{c}\text { Key } \\
\text { identification } \\
\text { feature }\end{array}$ & $\begin{array}{l}\text { Multilevel } \\
\text { Resolution }\end{array}$ & $\begin{array}{l}\text { Two } \\
\text { parallel } \\
\text { standard } \\
\text { DWT trees } \\
\text { in } \\
\text { quadrature }\end{array}$ & $\begin{array}{l}\text { Complex } \\
\text { mapping } \\
\text { followed } \\
\text { by any } \\
\text { DWT }\end{array}$ \\
\hline Shift invariance & & Yes & Yes \\
\hline $\begin{array}{l}\text { Directionality } \\
\text { (for 2D) }\end{array}$ & Poor & Good & Very Good \\
\hline $\begin{array}{l}\text { Phase } \\
\text { Information }\end{array}$ & No & Yes Good & $\begin{array}{l}\text { Yes Very } \\
\text { Good }\end{array}$ \\
\hline $\begin{array}{l}\text { Redundancy(for } \\
\text { 2D) }\end{array}$ & & Fixed & Fixed \\
\hline $\begin{array}{c}\text { Perfect } \\
\text { Reconstruction }\end{array}$ & Yes & Yes & Yes \\
\hline $\begin{array}{l}\text { Decomposition } \\
\text { filter band } \\
\text { Structure }\end{array}$ & $\begin{array}{l}\text { Fixed } \\
\text { (2 Band) }\end{array}$ & $\begin{array}{l}\text { Fixed } \\
(2 \text { band })\end{array}$ & $\begin{array}{l}\text { Flexible } \\
\text { ( } 6 \text { band) }\end{array}$ \\
\hline Throughput & low & high & Very high \\
\hline Complexity & low & $\begin{array}{l}\text { High as } \\
\text { compared } \\
\text { to DWT }\end{array}$ & $\begin{array}{c}\text { High as } \\
\text { compared } \\
\text { to DTCWT }\end{array}$ \\
\hline Cost & low & High & Quite HIgh \\
\hline
\end{tabular}

\section{TABLE : CHARACTERISTIC COMPARISON OF DWT, DT CWT and DDDT CWT}

This comparative study suggests that we have studied the DWT computing system that can be implemented in verilog HDL and later on the result can be validated on FPGA. The proposed architecture provides us with good performance with respect to throughput, perfect reconstruction, directionality and phase information 


\section{ACKNOWLEDGEMENT}

Firstly I express my deep appreciation and liability to my project guide Prof. Ravi Mishra who had always been an asset and source of motivation throughout the project development and execution in all aspect of work. I want to convey my deep thanks to my guide for giving his precious time valued advice for project work with great interest.

\section{REFERENCES}

1) I.W. Selesnick, "The Double-Density DWT," IEEE Trans. Signal Processing, vol. 52, no.5, pp. 1304-1314,May 2004.

2) N.G. Kingsbury, "Complex wavelets for shift invariant analysis and filtering of signals," $J$. Applied and Computational Harmonic Analysis, vol. 10, no. 3, pp. 234-253,May 2001.

3) I.W. Selesnick, R.G. Baraniuk, and N.G. Kingsbury,"The Dual-Tree Complex Wavelet Transform,"IEEE Signal Proc.Magazine, vol. 22, no. 6, pp. 123-151, Nov. 2005.

4) I.W. Selesnick, "Hilbert Transform Pairs of Wavelet Bases," IEEE Signal Proc. Letters, vol. 8, no. 6, pp.170-173, June 2001.

5) R. Yu and H. Ozkaramanli, "Hilbert Transform Pairs of Orthogonal Wavelet Bases: Necessary and Sufficient Conditions," IEEE Trans. Signal Processing, vol. 53, no. 12, pp. 4723-4725, Dec. 2005.

6) B. Dumitrescu, "SDP Approximation of a Fractional Delay and the Design of Dual-Tree Complex Wavelet Transform," IEEE Trans. Signal Proc.,2008, to appear.

7) B. Dumitrescu, Positive trigonometric polynomials and signal processing applications, Springer, 2007.
8) T.N. Davidson, Z.Q. Luo, and J.F. Sturm, "Linear Matrix Inequality Formulation of Spectral Mask Constraints with Applications to FIR Filter Design," IEEE Trans. Signal Proc., vol. 50, no. 11, pp. 2702-2715, Nov. 2002.

9) B. Alkire and L. Vandenberghe, "Convex optimization problems involving finite autocorrelation sequences,"Math. Progr. ser. A, vol. 93, no. 3, pp.331-359, Dec. 2002.

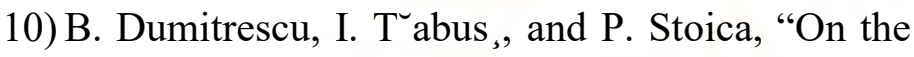
Parameterization Of Positive Real Sequences and MA Parameter Estimation," IEEE Trans. Signal Proc.,vol. 49, no. 11, pp. 2630-2639, Nov. 2001.

11) J.F. Sturm, "Using SeDuMi 1.02, a Matlab Tool box for Optimization over Symmetric Cones," Optimization Methods and Software, vol. 11, pp. 625-653, 1999, http://sedumi.mcmaster.ca.

12) C. Zhang, C. Wang, M. O. Ahmad, "A VLSI architecture for a fast computation of the 2-D discrete wavelet transform", Proc. IEEE Int. Symp. Circuits Syst. (ISCAS), pp. 3980-3983, May 2007

13) C. Y. Chen, Z. L. Yang, T. C. Wang, L. G. Chen, "A programmable VLSI architecture for 2-D discrete wavelet transform", Proc. IEEE Int. Symp. Circuits Systems (ISCAS), vol. 1, pp. 619622, 2000-May-2831.

14) M. Vishwanath, R. Owens, and M. J. Irwin, "VLSI architectures for the discrete wavelet transform," IEEE Trans. Circuits Syst. II, Analog. Digit. Signal Process, vol. 42, no. 5, pp. 305-316, May 1995.

15) S. Mallat, "A theory for multiresolution signal decomposition: The wavelet representation," IEEE Trans. Pattern Anal. Mach. Intell, vol.11, no. 7, pp. 674-693, Jul. 1989. 